\title{
Impact of Offspring Sex and Dam's Pre-partum Vaccination on Colostrum Composition and Blood Hormones in Egyptian Buffaloes
}

\author{
Mostafa Salah El-Din Ali ${ }^{1}$, Wafai Zaki Azir Mikhail ${ }^{2}$, Mohamed Amin Mohamed Salama ${ }^{1}$ and Yassin Mohamed \\ Hafez $^{3}$ \\ ${ }^{1}$ Animal Production Research Institute, Agriculture Research Centre, Dokki, Giza, Egypt. \\ ${ }^{2}$ Department of Natural Resources, Faculty of African Research and Studies, Cairo University, Giza, Egypt. \\ ${ }^{3}$ Animal Production Department, Faculty of Agriculture, Cairo University, Giza, Egypt. \\ *Corresponding author's Email: Mustafasalaheldin@hotmail.com; (D) ORCiD: 0000-0002-7810-0058
}

\begin{abstract}
The aim of the present research was to determine the effect of both the gender of the new-born calf and the prepartum vaccination status of the dam (ScourGuard-4K) on the chemical composition and some biological parameters of the colostrum. Blood serum was collected from four groups of pregnant dams (four animals in each group) during the dry period (vaccinated buffalo dams pregnant with a male fetus, vaccinated buffalo dams pregnant with a female fetus, unvaccinated buffalo dams pregnant with a male fetus, and unvaccinated buffalo dams pregnant with a female fetus), in the pregnancy period, at the giving-birth period and after 24 hours of postpartum. The levels of insulin-like growth factor hormone (IGF-1) and immunoglobuline $\mathrm{G}(\mathrm{IgG})$ were calculated in the maternal blood serum at the assigned periods. Colostrum samples were collected at the birth time and 6, 12, 24, 48, and 72 hours after birth for measuring the chemical composition of the colostrum, as well as levels of IgG and IGF-1. Results of the current study showed that colostrum of dams that gave birth to male fetus had a richer content of IgG and IGF-1 levels and a higher percentage of total solids, solids-not-fat, total protein, fat, and lactose. Additionally, vaccination improved the same colostrum components except for IGF-1, which was not positively influenced by the vaccination. Generally, colostrum components were the highest at the birth time, then it decreased gradually up to 72 hours after the birth except that for the percentage of fat and lactose which showed gradual increases up to 72 hours to reach the normal composition of milk.
\end{abstract}

Keywords: Blood hormones, Colostrogenesis, Egyptian buffaloes, Offspring sex, ScourGuard-4k

\section{INTRODUCTION}

The nutritional importance of colostrum to the new-borns has been shown by various studies (Joost et al., 2007; Stelwagen et al., 2009; Sobczuk-Szul et al., 2013), and other components of colostrum, especially fat and protein are important for the newly born calves' adaptation, development, and growth. Colostrum proteins also contain bioactive components, such as major milk proteins, hormones, growth factors, and cytokines interleukin 1- $\beta$ (IL-1 $\beta$ ) which serve as the stimulants and mediators in many processes taking place in cells (Elfstrand et al., 2002; McGrath et al., 2016). It also includes many antimicrobial, anti-viral, antifungal, and immunoregulating substances (Christiansen et al., 2010; Sobczuk-Szul et al., 2013).

In pregnant dairy animals, maternal and fetal blood supplies are separate; therefore, there is no macromolecules transfer across the placenta from the dam to the fetus (syndeschoroidal placenta), (Kuralkar and Kuralkar, 2010). Calves are born essentially agammaglobulinemic (Fox and McSweeney, 2003), and at the time of parturition, maternal Ig from the circulating pool in the blood is actively concentrated in the secretion of the mammary gland (Levieux and Ollier, 1999). The optimal passive transfer of immunoglobulins to calves through the colostrum occurs within the first 4-6 hours postpartum, and then gradual decrease of colostrum absorption in the calf's intestinal wall into the bloodstream continues up to 24 hours after the birth (Godden et al., 2009). Therefore, it is important to provide high-quality colostrum early to the newly born calves to satisfy their nutritional requirements and immunity requirements. Inadequate feeding of quality colostrum to the neonatal calf can result in reduced growth rates as well as increased risk of disease and death, particularly during the period that calves will gradually activate their own immune system (Smith and Foster, 2007; Szewczuk et al., 2011).

The calf's sex was shown to affect the amount of colostrum, concentration of fat, and amount of milk produced by lactating Holstein cows; all were higher in cows that gave birth to a female calf (Hinde et al., 2014). The concentration of IgG in the colostrum begins to decrease four hours after birth, while the concentration of protein in the colostrum decreases after the first hour of birth (Angulo et al., 2015). In addition, the quality of colostrum tended to be influenced 
by vaccination against pathogens prior to calving compared with unvaccinated herds as reviewed by Maunsell et al. (1998). Vaccination of the cow at 3-6 weeks prior to calving can lead to an increase in the number of antibodies in colostrum against those specific antigens. The antibodies (especially IgG) are transferred to the calf via colostrum to provide an effective means of preventing many diseases that calves are most susceptible to early in their life. On the other hand, in New Zealand, Denholm et al. (2017) and Denholm et al. (2018) reported that colostrum samples for vaccinated herds had a higher quality than samples for unvaccinated or only partial vaccinated herds.

Since high-quality colostrum is an important factor affecting the health of newborn calves, evaluation of quality is essential to obtain good health outcomes. Therefore, it is important to study the influence of fetus sex and pre-partum vaccination on the colostrogenesis process, and the chemical and biological composition of the colostrum for buffalo dams.

\section{MATERIALS AND METHODS}

The current study was carried out at Mehallet Moussa Experimental Station, Animal Production Research Institute, Agriculture Research Centre, Ministry of Agriculture and Land Reclamation, Egypt, from January to April 2017. Mehallet Moussa Experimental Station is located in the northern part of the Nile Delta, Egypt, at Latitude $31.7^{\circ}$ and $30.57^{\circ}$ on 20 meters above sea level. The experimental work including two stages, the first was maternal injection by ScourGuard 4k vaccine at the last gestation period during January and February months (the winter conditions), and the second was at birth and collection of colostrum samples for analysis during March and April (the spring conditions). The purpose of the present study was to investigate the effect of offspring sex and vaccination of pregnant buffalo dams on colostrum characteristics and some blood parameters.

\section{Vaccination system}

\section{Pre-experimental preparations before calving}

A total of 32 Egyptian buffalo dams at the late pregnancy period were assigned to the current study. Sixteen of these buffalo dams were vaccinated with ScourGuard $4 \mathrm{k}$ vaccine against Bovine Rotavirus, Coronavirus, and Escherichia Coli Bacteria by injecting $2 \mathrm{ml}$ intramuscularly, and they were revaccinated with the same dose after 3 weeks. The second dose was given 5 weeks before calving, according to the directions of Zoetis Inc (REF), Veterinary Services, USA.

\section{Blood samples collection before birth}

Three blood samples were collected from the jugular vein of each animal, every 15 days before the expected calving date, and the average concentration of maternal components of these three samples was used to express the concentration of these components around calving. The first sample was taken 2 weeks after the time of the first ScourGuard vaccination (at 8 weeks before the expected time of calving), then the second sample at 15 days after the first sample (after one week of the second dose of ScourGuard $4 \mathrm{~K}$ vaccination), the last sample was taken at 15 days prior to the expected time of calving. Serum samples were obtained after the centrifugation of coagulated blood at 4000 $\mathrm{rpm}$ for 15 minutes. The serum was separated and kept frozen at $-20^{\circ} \mathrm{C}$ until the time of analysis.

\section{Experimental design}

After calving and knowing the gender of newborn calves, 16 animals were selected for the experiment, and divided into four groups (four animals in each group). The first Group was unvaccinated buffalo dams pregnant with a male fetus. The second group was unvaccinated buffalo dams pregnant with a female fetus. The third group was vaccinated (ScourGuard 4K) buffalo dams pregnant with a male fetus. The fourth group was buffalo dams pregnant with a female fetus and vaccinated with ScourGuard $4 \mathrm{k}$. The experimental animals were kept under normal feeding and management conditions applied on the farm. All pregnant dams were fed the same diet according to the allowances suggested by Animal Production Research Institute (APRI), Agriculture Research Centre, Ministry of Agriculture and Land Reclamation, Egypt.

\section{Blood sample collection after birth}

The blood samples were collected pre-partum, at birth, and 24 hours postpartum. Serum samples were obtained after the centrifugation of coagulated blood at $4000 \mathrm{rpm}$ for 15 minutes. The serum was separated and kept frozen at $20^{\circ} \mathrm{C}$ until the time of analysis.

\section{Colostrum sample collection}

Colostrum samples were collected at 6 different times, including just after calving, and after 6, 12, 24, 48, and 72 hours of birth.

\section{Laboratory determination}

\section{Blood analysis}

A WKEA kit (Wkea Med Supplies Corporate, China) was used to assay Bovine Immunoglobulin G (IgG) and Insulin-like Growth Factor 1 (IGF-1) level in the bovine serum

\section{Colostrum analysis}

Colostrum samples were collected into two tubes. The first fresh tube was analyzed to determine the colostrum chemical analysis (total solids, total protein, lactose, fat, and solid-not-fat [SNF]) using the mid-infrared spectroscopy technique (Milkoscan 93, Foss Electric, Hillerod, Denmark). The second tube contained two drops of rennin enzyme to separate whey for measuring IgG and IGF-1 of the colostrum. A WKEA kit (Wkea Med Supplies Corporate, China) was 
used to assay Bovine Immunoglobulin G (IgG) and Insulin-like Growth Factor 1 (IGF-1) level in the colostrum whey samples.

\section{Ethical approval}

Animal manipulations and the experimental procedures were approved by the Ethical Committee of the Animal Production Research Institute, Agriculture Research Centre, Ministry of Agriculture and Land Reclamation, Egypt, the specific authorization reference number is ARC-25-17-30 and the date of approval is January 2017.

\section{Statistical analysis}

The data obtained were statistically analyzed by the least squares procedure of the general linear model (GLM) of SAS program (SAS, 2002). The separation of means was done using the Duncan's New Multiple Range Test (Duncan, 1955) for comparisons among the significant means. P value less than 0.05 was considered statistically significant.

The fixed model used in the analysis was:

$\mathrm{Y}_{\mathrm{ijk}}: \mu+\mathrm{G}_{\mathrm{i}}+\mathrm{T}_{\mathrm{j}}+(\mathrm{GT})_{\mathrm{ij}}+\mathrm{e}_{\mathrm{ijk}}$

Where, $Y_{i j k}$ refers to the observation on the $\mathrm{k}^{\text {th }}$ animals of the $\mathrm{i}^{\text {th }}$ group in the $\mathrm{j}^{\text {th }}$ time, $\mu$ denotes overall mean, $G_{i}$ signifies fixed effect due to the groups (i: 1: unvaccinated male; 2: unvaccinated female; 3: vaccinated male; 4: vaccinated female). $T_{j}$ is a fixed effect due to the time (j: $1:$ at birth; $2: 6$ hours after birth; 3: 12 hours after birth; $4: 24$ hours after birth; 5: 48 hours after birth; 6: 72 hours after birth). Moreover, $(G T)_{i j}$ shows the interaction between the group and time, and $e_{i j k}$ is a random error associated with the $\mathrm{ij} \mathrm{k}^{\text {th }}$ observation, and is assumed to be independently and normally distributed,

\section{RESULTS}

Table 1 shows the comparison of $\operatorname{IgG}$ concentration before birth and until 24 postpartum in the maternal serum of ScourGuard $4 \mathrm{~K}$ vaccinated and unvaccinated dams pregnant with male or female fetus.

The total IgG concentration in the maternal serum at the time of calving was found to be affected by the sex of the neonate, and it was higher when the dam carried a male fetus $(427.0 \pm 7.89 \mathrm{mg} / \mathrm{dl})$ than a female fetus $(298.75 \pm 8.22$ $\mathrm{mg} / \mathrm{dl}$ ) in the control group (unvaccinated, $\mathrm{p}<0.0001$ ). Additionally, the same trend of IgG concentration in the maternal serum at calving time was also shown even when the dams were vaccinated during the periparturient period as shown in Table 1 ( $\mathrm{p}<0.0001)$. No significant differences were detected in the levels of serum IgG concentrations 24 hours postcalving ( $\mathrm{p}=0.2895$ ), while dams pregnant with male fetus had higher serum IgG concentration before birth as compared to female fetus, especially in the vaccinated group as indicated in Table $1(\mathrm{p}=0.0302)$.

The total IgG concentration in the dam's serum during the periparturient period was not affected by the ScourGuard $4 \mathrm{~K}$ vaccination whether the dam pregnant with a male or a female fetus (Table $1 ; \mathrm{p}=0.2895$ ). However, ScourGuard $4 \mathrm{~K}$ vaccination significantly affected the IgG concentration (at the time of birth) in the serum of the dams (carried a female or a male fetus), where IgG concentrations were higher in the vaccinated groups (ScourGuard 4K), compared to the control (unvaccinated) as can be seen in Table 1 ( $\mathrm{p}<0.0001)$. On the contrary, no significant effects in the maternal serum IgG were detected due to the vaccination status at 24 hours post-calving as shown in Table 1 ( $\mathrm{p}=$ $0.2895)$.

As shown in Table 2, the influence of the offspring sex on IgG concentration in the colostrum began to be apparent in favor of dams carried male fetuses at $6,12,24$, and 48 hours postpartum, and then it disappeared at 72 hours postcalving in the unvaccinated group. There were significant differences at different time intervals on total IgG between groups (male and female vaccinated or unvaccinated) at birth time $(\mathrm{p}<0.01)$. Furthermore, there were significant differences between groups (male and female vaccinated or unvaccinated) regarding total IgG at $6,12,24,48$, and 72 hours $(\mathrm{p}<0.001)$.

The effect of fetus gender or dam's vaccination on IgG concentration in dam's serum almost disappeared after 24 hours of birth ( $p=0.2895$, Table 1$)$, while the effect of gender of newborn calves on $\mathrm{IgG}$ rate in colostrum continued after birth and up to 48 hours biased in favor of male deliveries $(p=0.0004$, Table 2$)$. The serum concentration of IGF-1 hormone for vaccinated and unvaccinated buffalo dams gave birth to male or female calves during the prepartum period, at birth and after 24 hours post-calving was shown to be not affected either by prepartum ScourGuard $4 \mathrm{~K}$ vaccination or gender of the fetus as shown in Table 3. There were significant differences at different times on total IGF-1 in favor of male fetus between groups (male and female vaccinated or unvaccinated) before birth $(\mathrm{p}<0.05)$ or at the birth time ( $\mathrm{p}<$ $0.05)$ until 24 hours after calving $(\mathrm{p}<0.001)$. Figure 1 shows that IGF-1 level in colostrum had the highest concentration at birth, then it decreased rapidly until the first 6 hours, and then it decreased gradually until 72 hours of birth. There was no significant effect of dam's vaccination on the level of the IGF-1 hormone in the colostrum $(p=0.2978)$, while there was a significant effect of fetus gender on IGF-1 level in colostrum $(p=0.0503)$. Figure 2 shows that the gender of the male fetus in addition to the prepartum Scour Guard $4 \mathrm{~K}$ maternal vaccination before birth exerted a positive effect in increasing the protein content in the colostrum $(\mathrm{p}<0.0001)$. Generally, it could be noticed that the highest value of protein in the colostrum was detected at the birth time followed by a gradual decrease up to the first 12 hours after the birth, and then it decreased sharply until 72 hours after birth to reach its ratio in milk $(\mathrm{p}<0.0001)$. 
From Figure 3, it could be observed that the percentage of fat in the colostrum of dams that gave male calves was higher compared to the fat in the colostrum of dams that gave birth to female calves $(\mathrm{p}<0.0001)$. Prepartum ScourGuard vaccination of buffalo dams had a slight effect in improving the fat percentage in the colostrum, whether in the case of male or female birth. The fat percentage increased gradually from the birth time up to 72 hours after birth ( $p<0.0001)$. The percentage of lactose in the colostrum was shown to be low at birth, and it remained low until the first 12 hours after birth, where it gradually increased until 72 hours after birth as illustrated in Figure 4 ( $<<0.0001)$. As shown in figures 5 and 6, total solids and SNF followed a similar shape as the protein curve, which is the main component of the SNF ( $p<$ 0.0001 and $p<0.0001$, respectively). It could be noticed that total solids and SNF decreased gradually during the first 12 hours after birth, and then they went in a sharp decrease until 72 hours after birth, especially in the colostrum of dams gave female birth. Fetus gender and dam's vaccination exerted a significant effect on total solids and SNF ( $p<0.0001$ and $\mathrm{p}<0.0001$, respectively).

Table 1. Serum IgG concentration before calving, at calving, and after 24 hours of calving for vaccinated/unvaccinated Buffalo dams gave (male/female) birth.

\begin{tabular}{|c|c|c|c|c|c|}
\hline \multirow{2}{*}{ Items } & \multicolumn{2}{|c|}{ Male } & \multicolumn{2}{|c|}{ Female } & \multirow{2}{*}{ P-value } \\
\hline & $\mathbf{C}$ & $\mathbf{V}$ & $\mathbf{C}$ & $\mathbf{V}$ & \\
\hline Before calving (mg/dl) & $254.50 \pm 22.03^{\mathrm{ab}}$ & $293.50 \pm 16.17^{\mathrm{a}}$ & $236.75 \pm 21.75^{\mathrm{ab}}$ & $206.25 \pm 6.73^{b}$ & $0.0302^{*}$ \\
\hline At calving (mg/dl) & $427.00 \pm 7.89^{b}$ & $463.00 \pm 11.85^{\mathrm{a}}$ & $298.75 \pm 8.22^{\mathrm{c}}$ & $402.00 \pm 2.86^{\mathrm{b}}$ & $<.0001^{* * * *}$ \\
\hline 24 hours after calving (mg/dl) & $225.50 \pm 17.93^{\mathrm{Ns}}$ & $299.00 \pm 6.09^{\mathrm{Ns}}$ & $320.25 \pm 67.01^{\mathrm{Ns}}$ & $298.75 \pm 7.41^{\mathrm{Ns}}$ & $0.2895^{\mathrm{Ns}}$ \\
\hline
\end{tabular}

Serum IgG concentration measured by $\mathrm{mg} / \mathrm{dl}$. C: Unvaccinated dams and V: Vaccinated dams. ${ }^{\text {a-b }}$ Values, within a row, with different superscripts are significantly different (Ns: Non-significant, $*$ : $p<0.05$ and $* * *: p<0.001$ ).

Table 2. Colostrum IgG concentration of the Buffalo during the first 72 hours after birth for vaccinated/unvaccinated Buffalo dams gave (male/female) birth.

\begin{tabular}{|c|c|c|c|c|c|}
\hline \multirow{2}{*}{ Items } & \multicolumn{2}{|c|}{ Male } & \multicolumn{2}{|c|}{ Female } & \multirow{2}{*}{ p value } \\
\hline & $\mathbf{C}$ & $\mathbf{V}$ & $\mathbf{C}$ & $\mathbf{V}$ & \\
\hline At birth (mg/dl) & $3500.00 \pm 117.84^{\text {ab }}$ & $3800.00 \pm 188.12^{\mathrm{a}}$ & $3200.00 \pm 120.20^{\mathrm{bc}}$ & $3000.00 \pm 69.87^{\mathrm{c}}$ & $0.0052^{* *}$ \\
\hline 6 hours after birth $(\mathrm{mg} / \mathrm{dl})$ & $2680.00 \pm 119.60^{\mathrm{ab}}$ & $2900.00 \pm 50.10^{\mathrm{a}}$ & $2300.00 \pm 58.45^{\mathrm{c}}$ & $2500.00 \pm 38.27^{\mathrm{bc}}$ & $0.0006^{* * *}$ \\
\hline 12 hours after birth $(\mathrm{mg} / \mathrm{dl})$ & $1700.00 \pm 43.27^{\mathrm{b}}$ & $1900.00 \pm 27.24^{\mathrm{a}}$ & $1500.00 \pm 16.71^{\mathrm{d}}$ & $1592.50 \pm 25.96^{\mathrm{c}}$ & $<.0001^{* * *}$ \\
\hline 24 hours after birth $(\mathrm{mg} / \mathrm{dl})$ & $1248.00 \pm 40.04^{\mathrm{a}}$ & $1300.00 \pm 17.96^{\mathrm{a}}$ & $1000.00 \pm 16.92^{\mathrm{c}}$ & $1099.25 \pm 24.46^{\mathrm{b}}$ & $<.0001^{* * *}$ \\
\hline 48 hours after birth $(\mathrm{mg} / \mathrm{dl})$ & $950.00 \pm 47.43^{\mathrm{b}}$ & $1100.00 \pm 25.20^{\mathrm{a}}$ & $850.00 \pm 12.57^{\mathrm{c}}$ & $900.00 \pm 19.92^{\mathrm{bc}}$ & $0.0004^{* * *}$ \\
\hline 72 hours after birth $(\mathrm{mg} / \mathrm{dl})$ & $440.00 \pm 20.74^{\mathrm{b}}$ & $600.00 \pm 23.21^{\mathrm{a}}$ & $450.00 \pm 7.05^{\mathrm{b}}$ & $445.00 \pm 18.43^{\mathrm{b}}$ & $0.0001^{* * *}$ \\
\hline
\end{tabular}

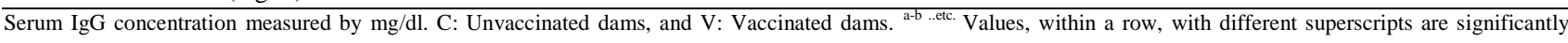
different at birth time $(* *: \mathrm{p}<0.01) ; 612,24,48$ and 72 hours $(* * *: \mathrm{p}<0.001)$.

Table 3. Serum hormone IGF-1 concentration for vaccinated/unvaccinated Buffalo dams gave birth (male/female) before calving, at calving, and after 24 hours of calving.

\begin{tabular}{|c|c|c|c|c|c|}
\hline \multirow{2}{*}{ Items } & \multicolumn{2}{|c|}{ Male } & \multicolumn{2}{|c|}{ Female } & \multirow{2}{*}{ P-value } \\
\hline & $\mathbf{C}$ & $\mathbf{V}$ & $\mathbf{C}$ & $\mathbf{V}$ & \\
\hline Before calving (mg/dl) & $180.02 \pm 0.96^{\mathrm{ab}}$ & $181.05 \pm 0.49^{\mathrm{a}}$ & $177.64 \pm 0.87^{b}$ & $177.92 \pm 0.78^{\mathrm{b}}$ & $0.0283^{*}$ \\
\hline At calving (mg/dl) & $177.11 \pm 0.62^{\mathrm{a}}$ & $176.00 \pm 0.75^{\mathrm{ab}}$ & $175.09 \pm 0.76^{\mathrm{ab}}$ & $174.05 \pm 0.63^{\mathrm{b}}$ & $0.0489^{*}$ \\
\hline 24 hours after calving $(\mathrm{mg} / \mathrm{dl})$ & $161.00 \pm 0.74^{\mathrm{a}}$ & $160.05 \pm 0.66^{\mathrm{ab}}$ & $157.03 \pm 0.67^{\mathrm{c}}$ & $158.06 \pm 0.87^{\mathrm{bc}}$ & $0.0097^{* *}$ \\
\hline
\end{tabular}

Serum IgG concentration measured by $\mathrm{mg} / \mathrm{dl}$. C: Unvaccinated dams and V: Vaccinated dams. ${ }^{\mathrm{a}-\mathrm{b}}$ Values, within a row, with different superscripts are significantly different $(*: \mathrm{p}<0.05$ and $* *: \mathrm{p}<0.01)$.
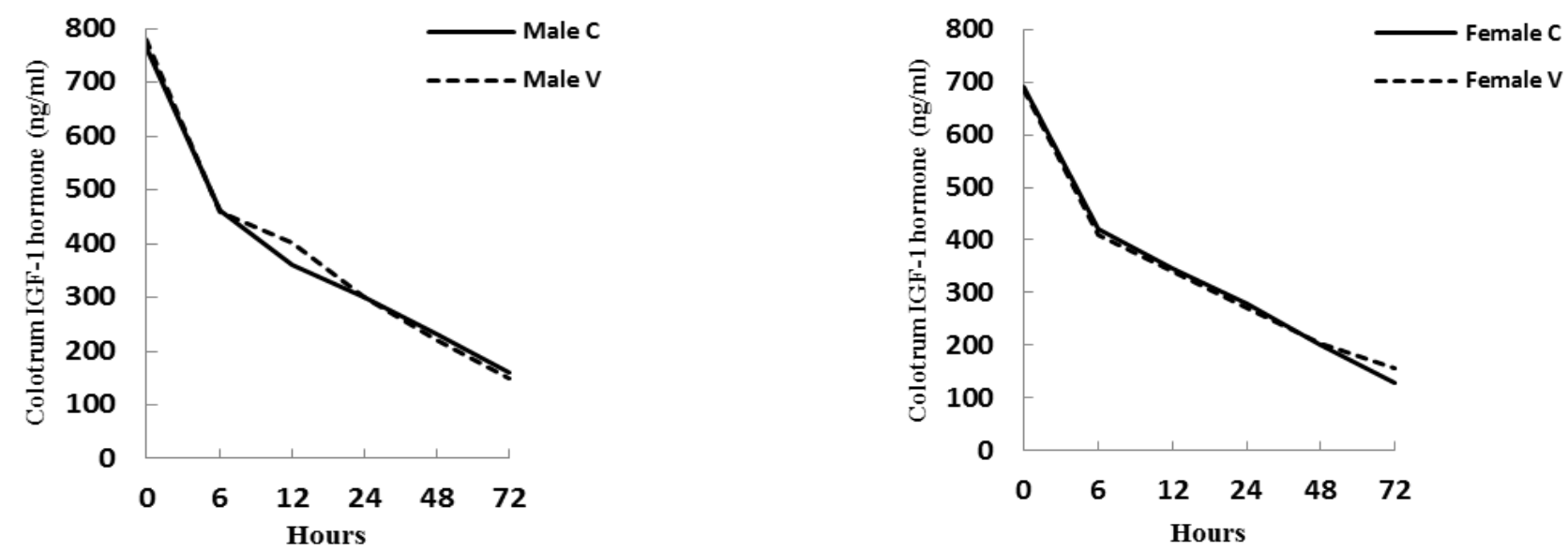

Figure 1. IGF-1 concentration (ng/ml) of the Colostrum for vaccinated and unvaccinated dams gave (male/ female) birth 

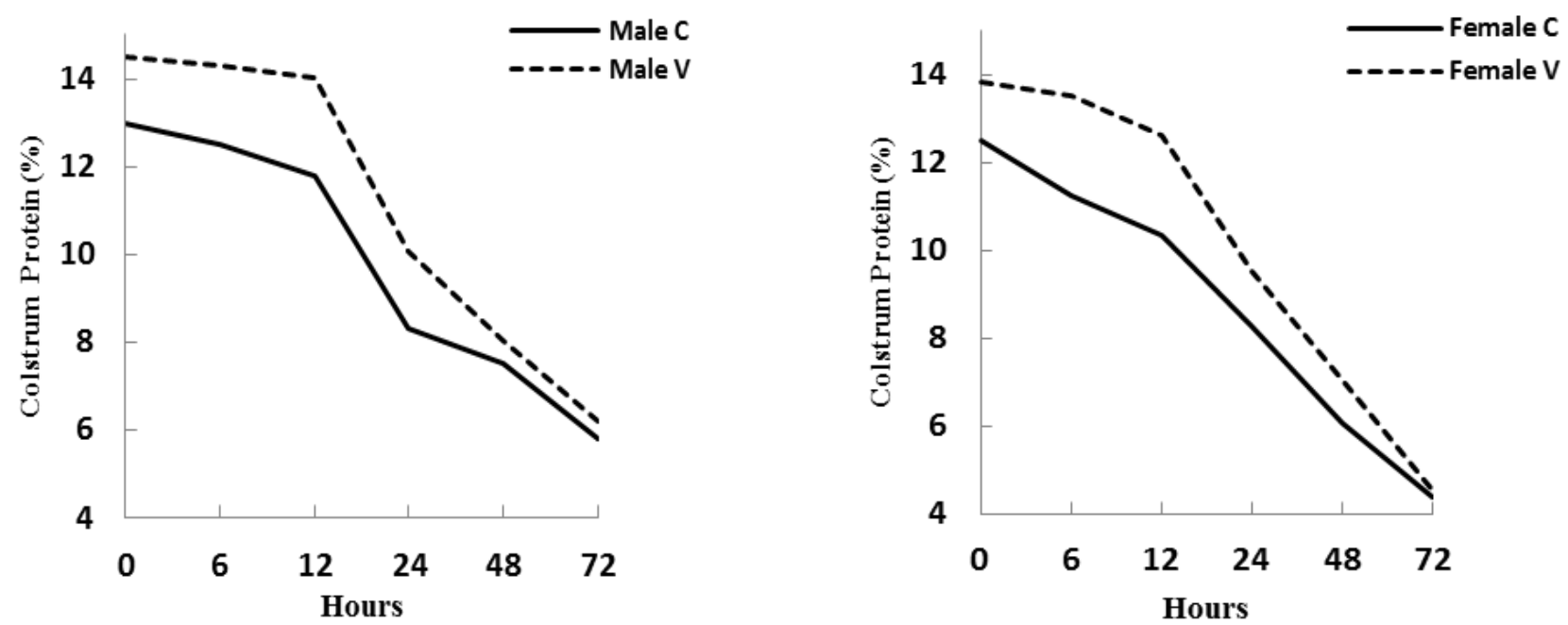

Figure 2. protein percentage of the colostrum for vaccinated and unvaccinated dams gave (male/ female) birth
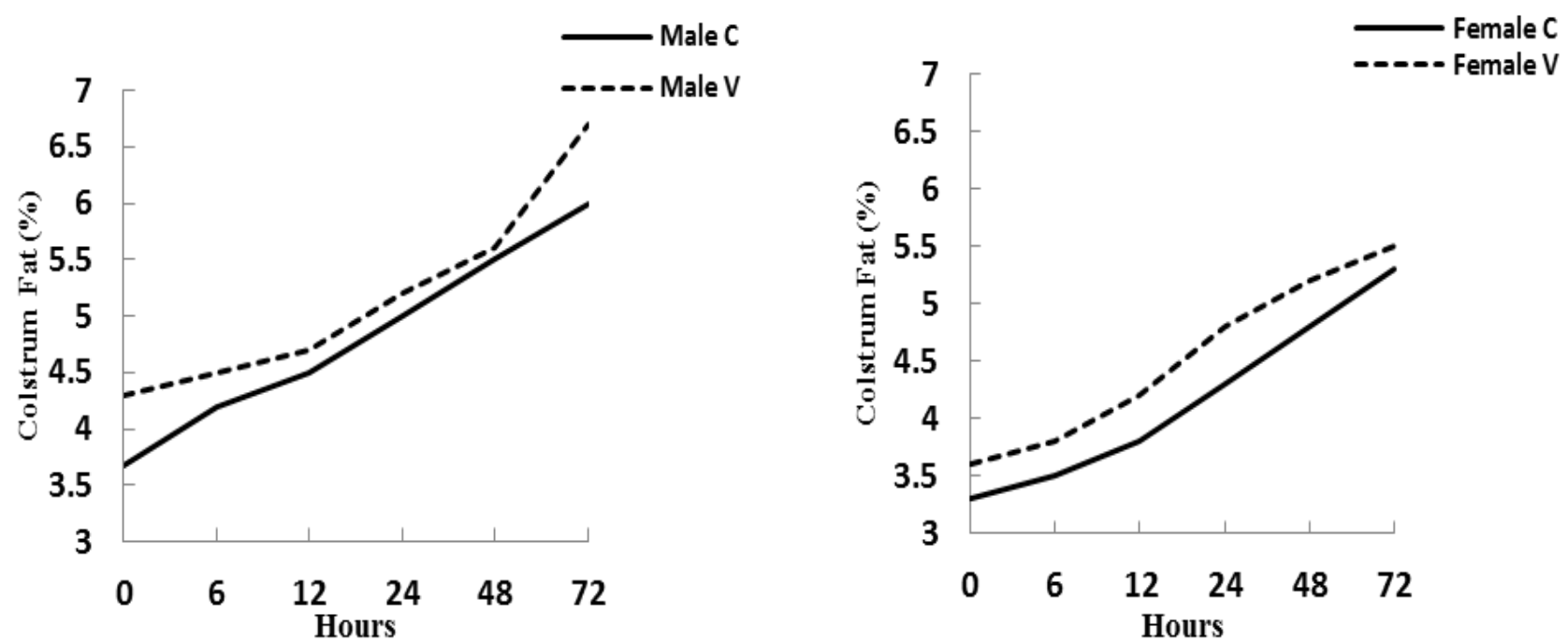

Figure 3. Fat percentage of the Colostrum for vaccinated and unvaccinated dams gave (male/ female) birth
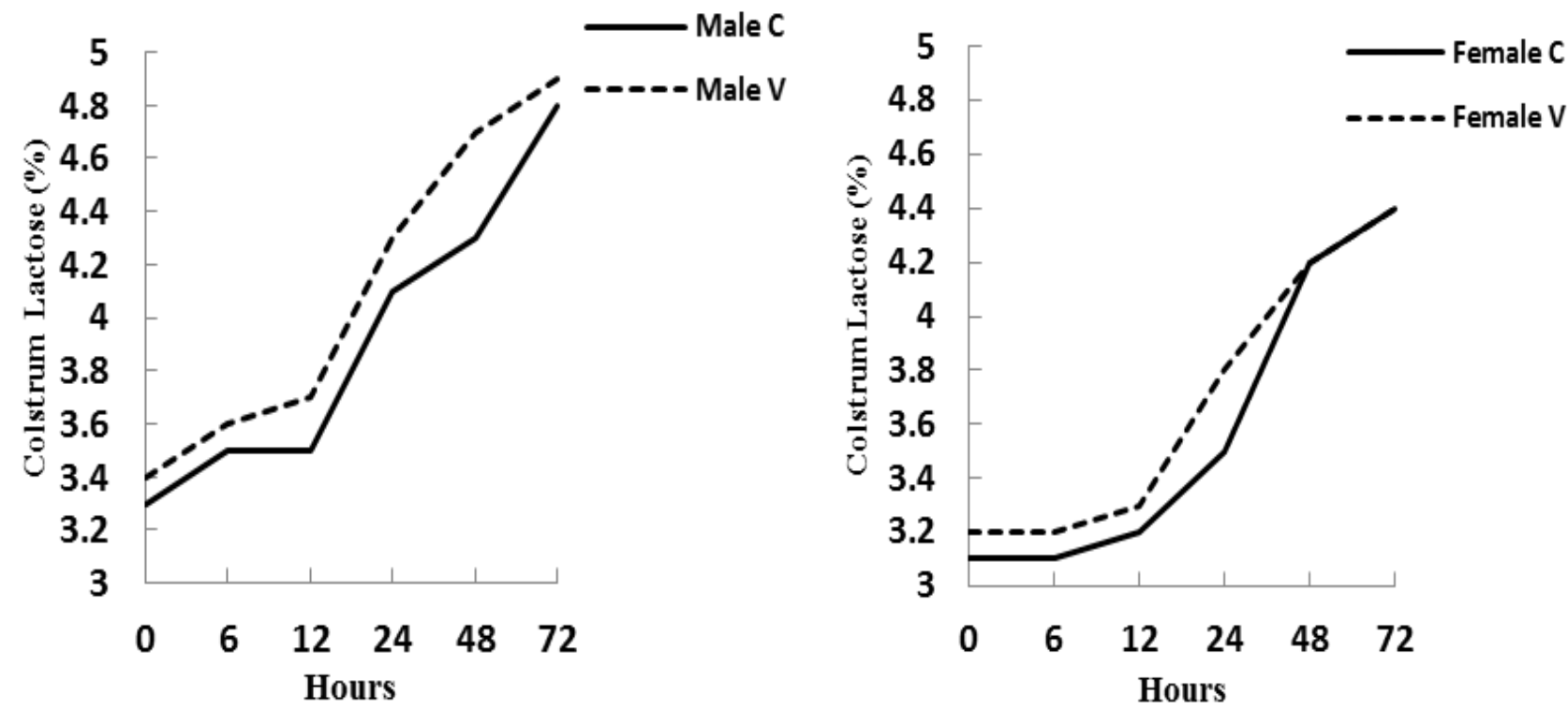

Figure 4. lactose percentage of the colostrum for vaccinated and unvaccinated dams gave (male/ female) birth 

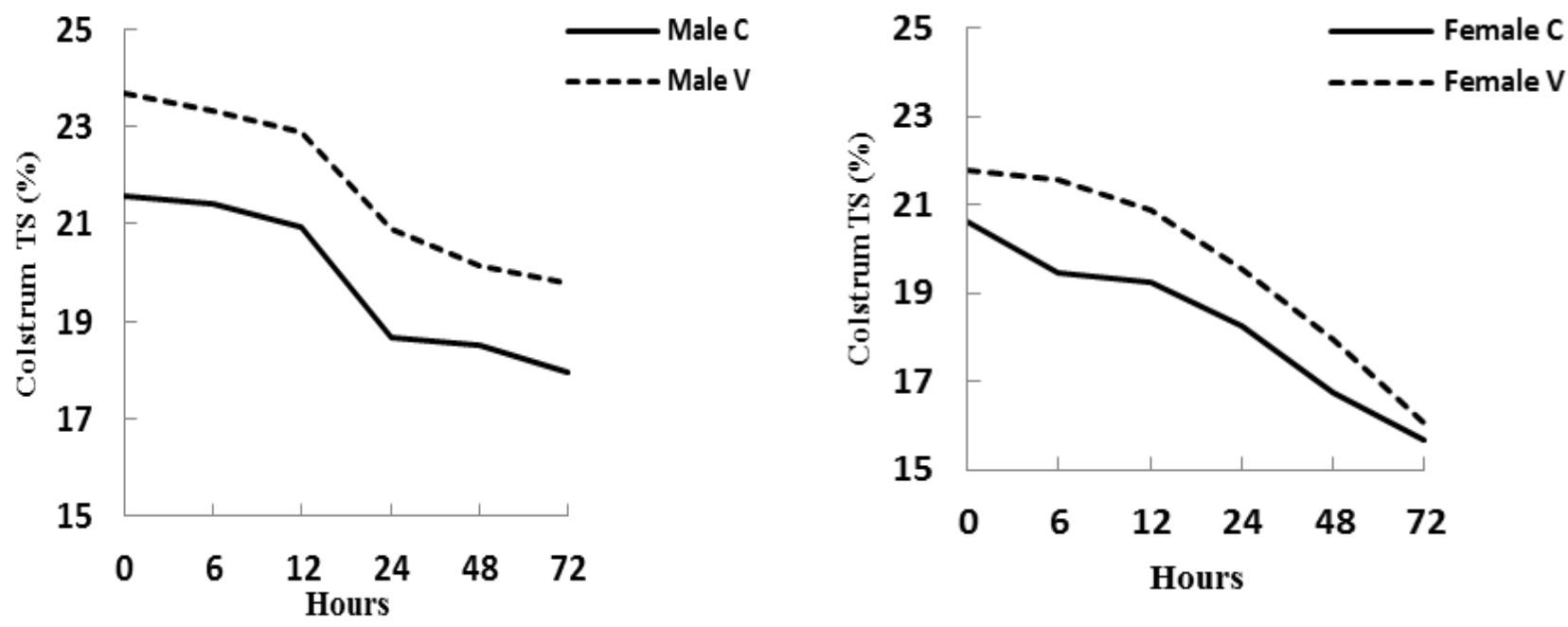

Figure 5. Colostrum total solid percentage for vaccinated and unvaccinated dams gave (male/ female) birth
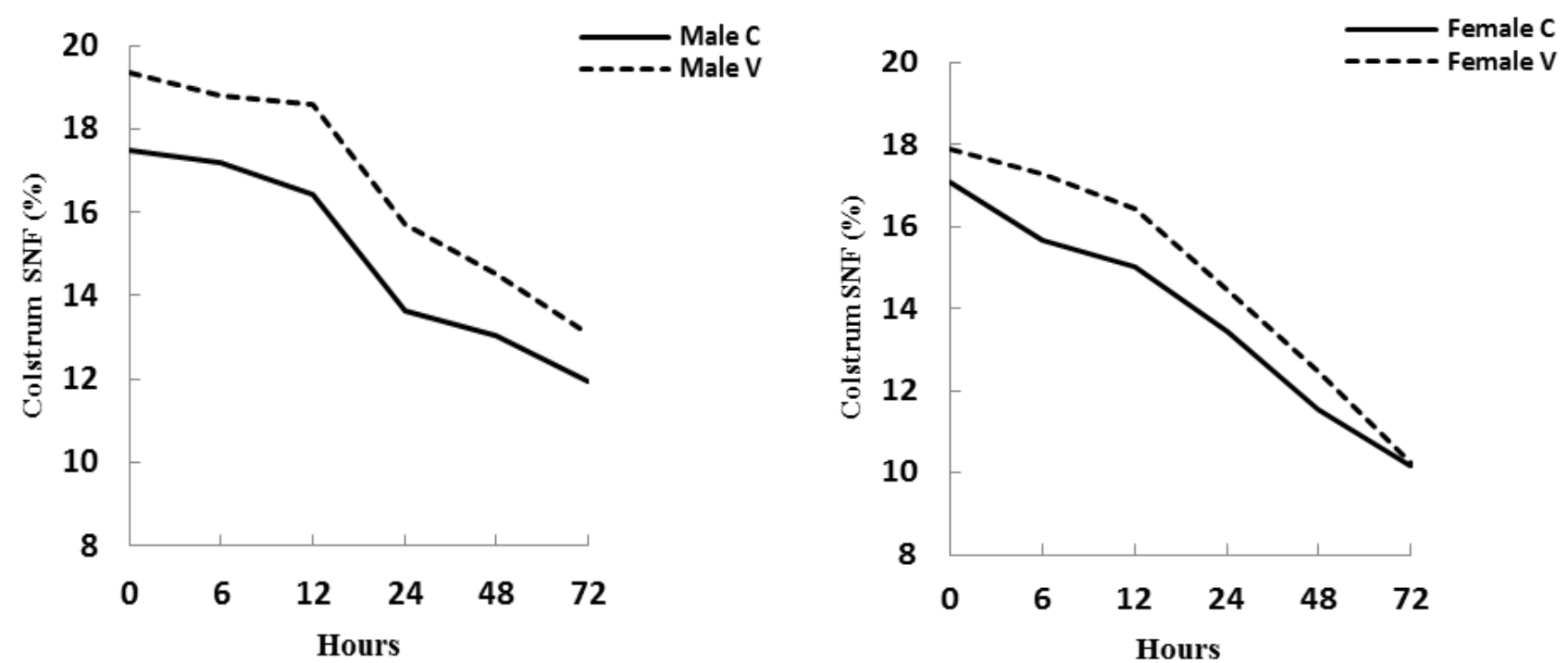

Figure 6. Solid-not-fat percentage of the colostrum for vaccinated and unvaccinated dams gave (male/ female) birth.

\section{DISCUSSION}

\section{IgG concentration}

Total serum and colostrum IgG concentration for buffalo dams were higher in dams carrying males than for those carrying females. This result might be due to fetal and placental hormones that may differ between male and female fetuses, and subsequently enter the maternal bloodstream affecting the milk-producing cells in the mammary glands (Hinde et al., 2014; Angulo et al., 2015). Some other researchers reported that the sex of the calf might influence maternal serum immunoglobulins. These results were not in accordance with the results of Norman and Hohenboken, (1981) indicating that sex of offspring did not affect IgG concentration in the dam's serum, and subsequently is transferred to the colostrum as reported by Ashmawy (2015b), who reported that colostrum IgG was identical to those of maternal blood serum. The results of the current study also supported the results published by Hinde et al. (2014), where they demonstrated that sex of the fetus in the uterus can either enhance or reduce milk production during the breastfeeding period in Holstein cows. Moreover, they suggested that hormones from the fetus and placenta may differ between fetal males and females, which subsequently enter the maternal bloodstream, and affect the production of colostrum and milk-producing cells in the mammary glands. The current results were in contrast to the report of Silper et al. (2012) showing that the total IgG concentration in colostrum of crossbred Holstein-Zebu cows were not affected by the sex of the fetus. This may be due to a dilution effect because the cows with a female calf produced higher amounts of colostrum than cows with a male calf (Angulo et al., 2015). Additionally, Kehoe et al. (2007) found that the concentration of $\mathrm{IgG}$ decreased as colostrum volume increased since there was no difference in the total amount of $\operatorname{IgG}$ produced (relating IgG concentration with the volume of produced colostrum). 
Colostrum IgG concentration during the first 48 hours after birth was higher for vaccinated Buffalo dams giving male birth. Hayr et al. (2015) mentioned that a male fetus typically has longer gestations than a female fetus, while colostrogenesis has been thought to be a very slow process that taken weeks to achieve the higher concentrations of IgG (Baumrucker and Bruckmaier, 2014). This might be one of the explanations why IgG concentration was greater in the colostrum of dams that gave birth to males. Xu et al. (2006) detected that vaccinated bovine had higher immunoglobulin concentration in serum and colostrum than unvaccinated groups. Moreover, vaccinated dams who gave birth to males kept their superiority in IgG level in colostrum up to 72 hours (Abd El-Fattah et al., 2012).

\section{IGF-1 concentration}

The reduction in IGF-1 level in colostrum during the first 72 hours agreed with Elfstrand et al. (2002) who found that IGF-1 concentration was at the highest level in the colostrum samples collected during the first 6 hours postpartum. Its concentration was reduced by $44 \%$ already after 11-20 hours. Moreover, it was reported by Abd El-Fattah et al. (2012) that the IGF-1 concentration in colostrum of buffalo dams reduced significantly by $20-40 \%$ after 6 hours of parturition by $77.44 \%$ after 5 days post-partum. There was an effect of fetus gender on serum IGF-1 concentration in favor of male fetus, whether they were vaccinated or unvaccinated, but it did not reach the level of significance, whether it was before birth or at the birth time until 24 hours after parturition.

In agreement with the current results, there was an increase in IGF-1 before calving was possible to be explained (Lucy et al., 2001) meaning that late pregnant dams (carried male fetuses) increased the secretion of growth hormone stimulating the secretion of IGF-1. On the other hand, Etherton (2004) elucidated that the action of GH hormone on the mammary gland is mediated mainly by IGF-1 hormone. Elevated levels of IGF-1 enhanced the stimulation of long bone growth, increased nutrient availability, and enhanced muscle tissue accretion (Lowe, 1990; Fiorotto et al., 2003). This was reflected in the higher birth weight in males than females in most cases. On the other hand, Kumar and Laxmi, (2015) suggested that IGF-1 could act as a paracrine/autocrine factor in the differentiation and activity of fetal Leydig cells, as IGF-1 receptors have been localized in Leydig cells and Sertoli cells in the testis. This may be one of the explanations in that IGF-1 level at birth was slightly increased in favor of dams that gave birth to males. The concentration of IGF-1 was higher in the colostrum, compared to the dam's blood unlike some other hormones as somatotropin, glucagon, and thyroid hormones (Georgiev, 2008). Ashmawy (2015a) indicated that colostrum has a higher concentration of IGF-1 hormone than in mature milk, but it rises again by the end of milking.

\section{Colostrum chemical analysis \\ Colostrum protein}

Hernández-Castellano et al. (2014) reported more than 200 different types of proteins in colostrum whey. Moreover, Tang et al. (2011) pointed that immunoglobins play the most important role in innate immune transfer. It was previously reported by Brian et al. (2016) that immunoglobulins make up 70-80\% of the total protein in colostrum, which represent most of the immune bodies transported from maternal blood to colostrum. Additionally, about $90 \%$ of colostrum immunoglobulins are being in the form of IgG (Georgiev, 2008), and the whey protein values of the colostrum samples obtained from the animals gave male calves were significantly higher than those animals that gave female calves (Nazir et al., 2018). This result agreed with Ashmawy (2015a) who indicated that the most consistent change occurring in the chemical composition of colostrum is in protein content where it is reduced by half of its concentration at one day postpartum compared to the initial value. A comparable result was reported by Elfstrand et al. (2002) as the total protein content in colostrum decreased with the time from birth during the first 82 hours after birth.

\section{Colostrum fat}

The percentage of fat in the colostrum was affected in favor of dams that had given birth to males. The same results were indicated by Nazir et al. (2018). The percentage of fat in colostrum gradually increases during the first 72 hours to reach a percentage in whole milk (Rauprich et al., 2000; Ashmawy, 2015a). However, conflicting results were mentioned by Abd El-Fattah et al. (2012), Nazir et al. (2018), and Wasowska and Puppel (2018) pointing that the fat content of colostrum is greater than that of milk. It seems that the type of fatty acids that makes up the colostrum fats differ from those in milk fats. Additionally, colostrum had a lower amount of trans saturated fatty acids and a higher amount of unsaturated fatty acids (Bitman and Wood, 1990; Elfstrand, 2002).

\section{Colostrum lactose}

Both vaccination and the gender of the male baby improved the percentage of lactose in the colostrum. The low lactose concentration during the first 12 hours after birth might reduce the chance of nutritional diarrhea. The findings of the current study were in agreement with these reported by Nazir et al. (2018), they noticed that the lactose content of colostrum for dams that delivered a male calf was significantly higher than that of dams gave female calves.

\section{Colostrum total solid and solid-not-fat}

Total solids in the colostrum are affected by the change of the various sediment components, especially protein, so their rate increases in the colostrum of immunized mothers who have given birth to males. Similar trends have been reported by Raducan et al. (2013) and Nazir et al. (2018). 
The gender of the male fetus, as well as the vaccination of dams before the parturition, led to an increase in total solid, solid-not-fat, total protein, fat, lactose, and IgG level in the colostrum. The male newborn calf increases IGF-1 level in the colostrum, while the vaccination of dams did not affect the level of IGF-1 in the colostrum. It could be concluded that although mothers who give birth to females give more milk yield, mothers who give birth to males give colostrum higher in nutritional and vital values. Therefore, it is possible to recommend when making a colostrum bank, it is preferable to take colostrum from vaccinated dams that gave birth to males.

\section{Acknowledgments}

Special thanks to the officials and employees of the Mehallet Moussa Experimental Station for providing partial funds by providing experimental animals and providing technical support for vaccination and sample collection. Sincere thanks to the staff members of Buffalo Research Department, Animal Production Research Institute, especially Dr. Laila Naser, Dr. Tarek Fooda, Dr. Faiza Omran, and Dr. Said Ahmed, for their help and kind guidance.

\section{DECLARATIONS}

\section{Authors' contribution}

Dr. Mostafa Salah El-din designed the study, cured the data, performed the practical part of the experiment, prepared and drafted the manuscript. Dr. Wafai Zaki Azer Mikhail participated in reviewing the manuscript, Dr. Mohamed Amin Mohamed Salama performed the statistical analysis, Dr. Yassin Mohamed Hafez supervised and followed-up the practical part and chemical analysis, and the authors declare that they checked and confirmed all data and the final version of the article.

\section{Competing interests}

The authors declare that they have no competing interests.

\section{REFERENCES}

Abd El-Fattah AM, Abd Rabo FH, El-Dieb SM, and El-Kashef HA (2012). Changes in composition of colostrum of Egyptian buffaloes and Holstein cows. BMC Veterinary Research, 8: Article number: 19. DOI: https://www.doi.org/10.1186/1746-6148-8-19

Angulo J, Gómez LM, Mahecha L, Mejía E, Henao J, and Mesa C (2015). Calf's sex, parity and the hour of harvest after calving affect colostrum quality of dairy cows grazing under high tropical conditions. Tropical Animal Health and Production, 47(4): 699-705. DOI: https://www.doi.org/10.1007/s11250-015-0781-z

Ashmawy NA (2015a). Chemical composition, hormonal levels and immunoglobin G concentration in colostrum, milk and blood plasma of Egyptian buffaloes following calving. International Journal of Advanced Research, 3(7): 471-478. Availabe at: https://www.journalijar.com/article/5315/chemical-composition,-hormonal-levels-and-immunoglobin-g-concentration-in-colostrums,-milk-andblood-plasma-of-egyptian-buffaloes-following-calving/

Ashmawy NA (2015b). Blood metabolic profile and certain hormones concentration in Egyptian buffalo during different physiological states. Asian Journal of Animal and Veterinary Advances, 10(6): 271-280. DOI: https://www.doi.org/10.3923/ajava.2015.271.280

Baumrucker CR, and Bruckmaier RM (2014). Colostrogenesis: IgG1 transcytosis mechanisms. Journal of Mammary Gland Biology and Neoplasia, 19: 103-117. DOI: https://www.doi.org/10.1007/s10911-013-9313-5

Bitman J, and Wood DL (1990). Changes in milk fat phospholipids during lactation. Journal of dairy science, 73(5): 1208-1216. DOI: https://www.doi.org/10.3168/jds.S0022-0302(90)78784-X

Christiansen S, Guo M, and Kjelden D (2010). Chemical composition and nutrient profile of low molecular weight fraction of bovine colostrum. International Dairy Journal, 20(9): 630-636. DOI: https://www.doi.org/10.1016/j.idairyj.2009.12.005

Denholm KS, Hunnam JC, Cuttance EL, and McDougall S (2017). Associations between management practices and colostrum quality on New Zealand dairy farms. New Zealand Veterinary Journal, 65(5): 257-263. DOI: https://www.doi.org/10.1080/00480169.2017.1342575

Denholm KS, McDougall S, Chambers G, and Clough W (2018). Factors associated with colostrum quality in individual cows from dairy herds in the Waikato region of New Zealand. New Zealand Veterinary Journal, 66(3): 115-120. DOI: https://doi.org/10.1080/00480169.2017.1418684

Duncan DB (1955). The Multiple Ranges and multiple F-Tests. Biometrics, 11: 1-42. Available at: http://garfield.library.upenn.edu/classics1977/A1977DM02600001.pdf

Elfstrand L, Lindmark-Månsson H, Paulsson M, Nyberg L, and Åkesson B (2002). Immunoglobulins, growth factors and growth hormone in bovine colostrum and the effects of processing. International Dairy Journal, 12(11): 879-887. DOI: https://www.doi.org//10.1016/S0958$\underline{6946(02) 00089-4}$

Etherton TD (2004). Somatotropic function: The somatomedin hypothesis revisited. Journal of Animal Science, 82: 239-244. DOI: https://www.doi.org/ 10.2527/2004.8213

Fiorotto ML, Schwartz RJ, and Delaughter MC (2003). Persistent IGF-1 overexpression in skeletal muscle transiently enhances DNA accretion and growth. FASEB Journal, 17(1): 59-60. DOI: https://www.doi.org/10.1096/fj.02-0289fje

Fox PF, and McSweeney PLH (2003). Advanced Dairy Chemistry, 3th ed.; Kluwer Academic/Plenum Publishers: New York, NY, USA; Proteins. Parts A\&B, 1: 1-48. Available at: https://www.springer.com/gp/book/9781441986023

Georgiev IP (2008). Differences in chemical composition between cow colostrum and milk. Bulgarian Journal of Veterinary Medicine, 11(1): 3-12. Available at: http://www.uni-sz.bg/bjvm/vol11-no1-01.pdf 
Godden SM, Haines DM, Konkol K, and Peterson J (2009). Improving passive transfer of immunoglobulins in calves. II: interaction between feeding method and volume of colostrum fed, Journal of Dairy Science, 92(4): 1758-1764. DOI: https://www.doi.org/10.3168/jds.2008-1847

Hayr MK, Hess AS, and Garrick DJ (2015). Impact of including calf gender in models to predict breeding value for lactation yields in dairy cattle. Animal Industry Report, 661: ASL R2966. DOI: https://www.doi.org/10.31274/ans_air-180814-1287.

Hernández-Castellano LE., Almeida AM, Castro N, and Argüello A (2014). The colostrum proteome, ruminant nutrition and immunity: A review. Current Protein and Peptide Science, 15(1): 64-74. DOI: https://www.doi.org/10.2174/1389203715666140221124622

Hinde K, Carpenter AJ, Clay JS, and Bradford BJ (2014). Holesteins favor heifers, not bulls: Biased milk production programmed during pregnancy as a function of fetal sex. PloS Oen, 9: e86169. DOI: https://www.doi.org/101371/Journal pone. 0086169

Joost J, Van Den Borne GC, Lobley GE, Verstegen MW, Muijlaert J, Alferink SJ, and Gerrits WJ (2007). Body fat deposition does not originate from carbohydrates in milk-fed calves, Journal of Nutrition, 137: 2234-2241. DOI: https://www.doi.org/10.1093/jn/137.10.2234

Kehoe SI, Jayarao BM, and Heinrichs AJ (2007). A survey of bovine colostrum composition and colostrum management practices on Pennsylvania dairy farms. Journal of Dairy Science, 90: 4108-4116. DOI: https://www.doi.org/10.3168/jds.2007-0040

Kumar A, and Laxmi N A. (2015). Role of IGF 1 in male and female reproduction in Bovines: A review. Asia Pacific Journal of Research, 1(24): 1725 .

Kuralkar P, and Kuralkar SV (2010). Nutritional and immunological importance of colostrum for the new born. Veterinary World, 3 (1): $46-47$. http://www.veterinaryworld.org/Vol.3/January/14.html

Levieux D, and Ollier A (1999). Bovine immunoglobulin G, beta-lactoglobulin, alpha-lactalbumin and serum albumin in colostrum and milk during the early post-partum period. Journal of Dairy Research, 66: 421-430. DOI: https://www.doi.org/ 10.1017/s0022029999003581

Lowe WLJr (1990). Biological actions of insulin like growth factors: Molecular and Cellular Aspects. CRC Press, Boca Raton, FL. USA. International standard book number, 3: 49-86.

Lucy MC, Jiang H, and Kobayashi Y (2001). Changes in the somatotrophic axis associated with the initiation of lactation. Journal of Dairy Science, 84: 113-119. DOI: https://www.doi.org/10.3168/jds.S0022-0302(01)70205-6

Maunsell FP, Morin DE, Constable PD, Hurley WL, McCoy GD, Kakoma I, and Isaacson RE (1998). Effects of mastitis on the volume and composition of colostrum produced by Holstein cows. Journal of Dairy Science, 81: 1291-1299. DOI: https://www.doi.org/10.3168/jds.S0022$\underline{0302(98) 75691-7}$

Mcgrath BA, Fox PF, Mcsweeney PLH, and Kelly AL (2016). Composition and properties of bovine colostrum: a review. Dairy Science and Technology, 96 (2): 133-158. DOI: https://www.doi.org/10.1007/s13594-015-0258-X

McGrath BA, Fox PF, McSweeney PLH, and Kelly AL (2016). Composition and properties of bovine colostrum: A review. Dairy Science and Technology, 96: 133-158. Available at: https://link.springer.com/article/10.1007/s13594-015-0258X\#: :text=In\%20general\%2C\%20colostrum\%20contains\%20less,3\%20days\%20of\%20lactation\%20(Blum

Nazir T, Pal MA, Baba FA., Manzoor A, Sofi AS, and Ahmad SR (2018). Effect of the sex of new born during various days of transition period on various physico-chemical, compositional and microbiological characteristics of bovine colostrum. International Journal of Livestock Research, 8(12): 233-246. DOI: https://www.doi.org/10.5455/ijlr.20180507014059.

Norman LM, and Hohenboken WD (1981). Genetic differences in concentrations of immunoglobulins G1 and M in serum and colostrum of cows and in serum of neonatal calvesJournal of Animal Science, 53(6): 1465-1472.

Raducan GG, Acatincai S, Cziszter LT, Tripon I, and Baul S (2013). Contributions to the knowledge of chemical composition evolution in colostral milk. Animal Science and Biotechnologies, 46(2): 322-324. Available at: http://spasb.ro/index.php/spasb/article/view/197/300

Rauprich AB, Hammon H, and Blum JW (2000). Influence of feeding different amounts of first colostrum on metabolic, endocrine, and health status and on growth performance in neonatal calves. Journal of Animal Science, 78(4): 896-908. DOI: https://www.doi.org/10.2527/2000.784896x

SAS (2002). SAS User's Guide. Statistical Analysis System. Institute, Inc., Cary. NC.

Silper BF, Coelho SG, Madeira MMF, Ruas JRM, Lana AMQ, Reis RB, and Saturnino HM (2012). Colostrum quality evaluation and passive immunity transfer in crossbred Holstein Zebu cattle. Arquivo Brasileiro de Medicina Veterinária e Zootecnia, 64: 281-285. Available at: https://www.scielo.br/scielo.php?pid=S0102-09352012000200005\&script=sci_abstract\&tlng=en

Smith GW, and Foster DM (2007). Absorption of protein and immunoglobulin G in calves fed a colostrum replacer. Journal of Dairy Science, 90(6): 2905-2908. DOI: https://www.doi.org/10.3168/jds.2006-682

Sobczuk-Szul M, Wielgosz-groth Z, Wroski M, and Rzemieniewski A (2013). Changes in the bioactive protein concentrations in the bovine colostrum of Jersey and Polish Holstein-Friesian cows, Turk. Journal of Veterinary and Animal Sciences, 37 (1): $43-49$. DOI: https://www.doi.org/10.3906/vet-1107-42

Stelwagen K, Carpenter E, Haigh B, Hodgkinson A, and Wheeler T (2009). Immune components of bovine colostrum and milk. Journal of Animal Science, 87(13): 3-9. DOI: https://www.doi.org/10.2527/jas.2008-1377. Epub 2008 Oct 24

Szewczuk M, Zych S, and Czerniawska-Piątkowska E (2011). Association between IGF1/TasI polymorphism and milk traits of Polish HolsteinFriesian cows. Archiv für Tierzucht, 54: 10-17. DOI: https://www.doi.org/ 10.5194/aab-54-10-2011

Tang ZR, Sun ZH, Tang XS, Feng ZM, Zhou D, Xiao DF, Zhang B, and Li LL (2011). Dietary bovine lactoferricin improved gut microflora, benefited intestinal mucosal morphology and inhibited circular cytokines delivery in 21-day weaned piglets. Journal of Applied Animal Research, 39(2): 153-157. DOI: https://doi.org/10.1080/09712119.2011.565570

Wasowska E, and Puppel K (2018). Changes in the content of immunostimulating components of colostrum obtained from dairy cows at different levels of production. Journal of the Science of Food and Agriculture, 98: 5062-5068. DOI: https://www.doi.org/10.1002/jsfa.9043. Epub 2018 May 29

Xu LB, Chen L, Gao W, and Du KH (2006). Bovine immune colostrum against 17 strains of diarrhea bacteria and in vitro and in vivo effects of its specific IgG. Journal Vaccine, pp. 2131-2140. DOI: https://www.doi.org/10.1016/j.vaccine.2005.11.009. Epub 2005 Nov 15 